UCRL-ID-116123

\title{
Rockbursts as Opportunities for the Concealment of Nuclear Tests?
}

\author{
François E. Heuze
}

January 1994

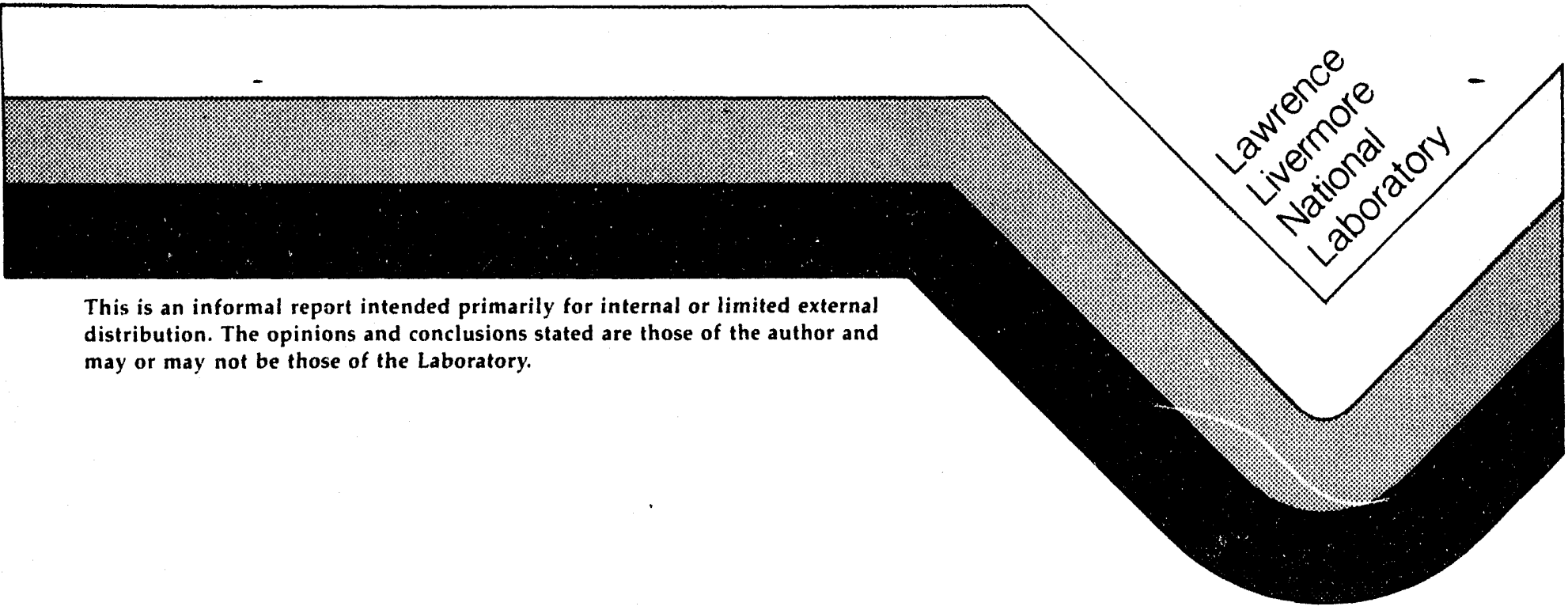




\section{DISCLAIMER}

This document was prepared as an account of work sponsored by an agency of the United States Government. Nelther the United States Government nor the University of Californis nor any of their employees, makes any warranty, express or implied, or assumes any legal liability or responsibility for the aceuracy, completeness, or usefulness of any information, apparatus, product, or process disclosed, or represents that its use would not infringe privately owned rights. Reference herein to any specific commercial products, process, or service by trade name, trademark, manufacturer, or otherwise, does not necessarily constitute or imply its endorsetnent, recommendation, or favoring by the United States Government or the University of Callfornia. The views and opinions of authors expressed herein do not necessarily state or reflect those of the United States Government or the University of California, and shall not be used for advertising or product endorsement purposes.

This report has been reproduced directly from the best available copy.

Avalable to DOE and DOE contractors from the Orifice of Scientific and Technical Information P.O. Box 62, Oak Ridge, TN 37831

Prices available from (615) 576-8401, FTS 626-8401

Available to the public from the

National Technical Information Service

U.S. Department of Commerce

5285 Port Royal Rd.

Springtield, VA 22161 


\section{CONTENTS}

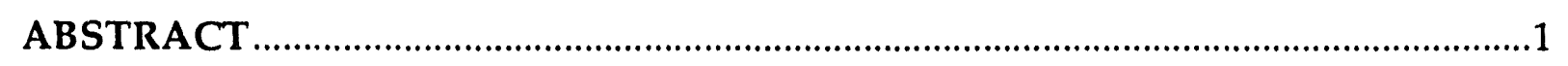

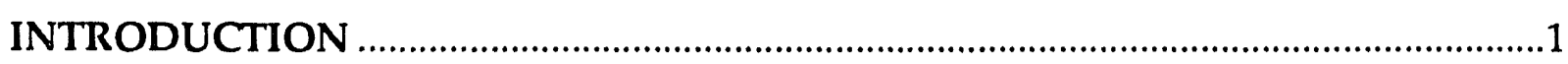

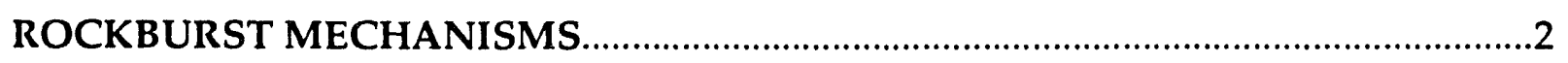

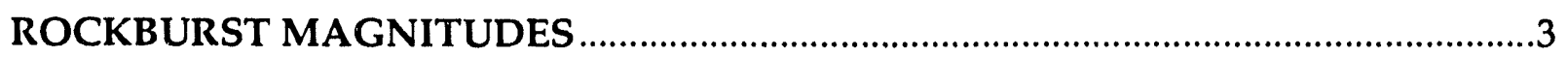

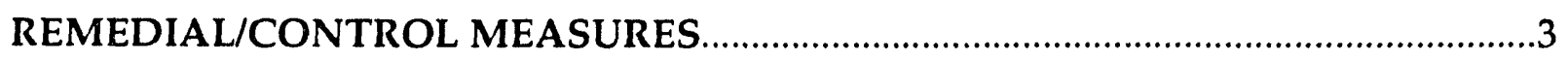

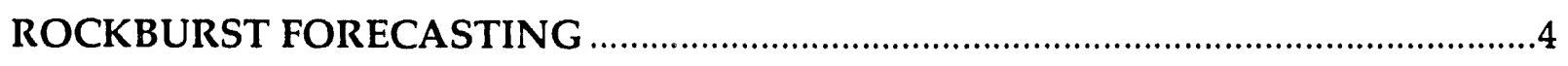

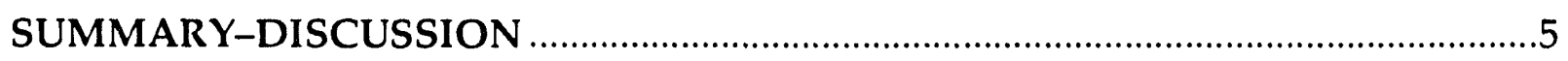

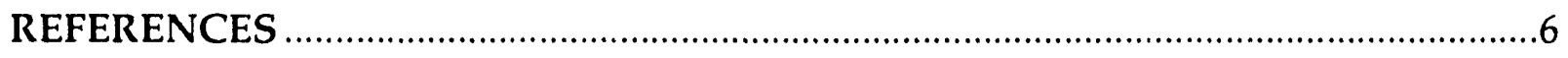

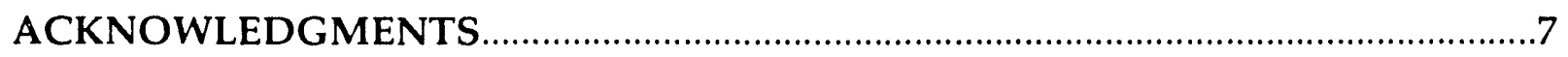




\begin{abstract}
Based on a review of the engineering and scientific literature from 1979 to 1993 concerning mine rockbursts, it is concluded that the hiding of nuclear tests in rockbursts is a highly improbable scenario. This is due to the lack of ability for anyone to accurately predict the time and location of occurrence of natural rockbursts, in spite of active research on the subject.

However, such an evasion scheme is not impossible. A contrived rockburst possibly could be made to happen in a somewhat "controlled" fashion. This rather farfetched scenario is outlined in the discussion. Such an event most likely would involve serious damage to the underground, and would be unlikely to be repeated frequently at any given site. Moreover, it would be extremely difficult to control its seismic magnitude.
\end{abstract}

\title{
INTRODUCTION
}

The purpose of this study was to ascertain the feasibility of hiding a nuclear test in a mine rockburst by firing the test concurrently with a rockburst which would have been predicted accurately in time and location. Thus the essential question to answer was: can one predict the time and location of rockbursts in a precise fashion.

One-hundred and ninety-two papers and reports on the subject of mine rockbursts and mine seismicity were analyzed. They cover the engineering and scientific literature from 1979 to 1993 . The bulk of these references is contained in the proceedings of three International Conferences on Rockbursts and Seismicity in Mines held in 1982, 1988, and 1993. The author also attended the $3^{\text {rd }}$ Conference, in Kingston, Ontario, august 16-18, 1993.

This summary report addresses the subjects of rockburst mechanisms and contributing factors, remediation/prevention methods, and forecasting methods. The discussion follows, and references are at the end of the text. 


\section{ROCKBURST MECHANISMS}

- Rockbursts generally are due to shear failure rather than volumetric breakage of rock ("compression" failure), such as may occur at a stope face. See:

- Bath, [2]", p 10, Sweden.

- Spottiswoode, [2], p 29, South Africa.

- Spottiswoode, [2], p 64. Makes the statement for "large" and "medium" events; magnitudes not specified.

- Kusznir et al., [2], p 159, U.K.; Shear source mechanisms for $M_{L} \geq 2.5$; implosional source for $\mathrm{M}_{\mathrm{L}}<2.5$. These are for coal fields.

- Gibowicz, [7], p 4, Poland. Shear events are usually "larger" than those of other type(s).

- Rockbursts are often related to major geologic features such as faults and dikes. See:

- Potgieter and Roering, [2], p 47, South Africa.

- Shepherd et al., [2] p 104, Australia.

- Gay, [2], p 111, South Africa.

- Von Antwerpen and Spengler, [2], p 235, South Africa.

- Brink and Mountfort, [2], p 317, South Africa.

- Gibowicz, [7], p 5, Poland. "Geologic factors" play the most important role in the generation of seismic events.

- Syratt, [7], p 77, South Africa. Seismic events occur along faults and dikes, but not all faults and dikes are seismically dangerous.

- Gay, [14], p 59, South Africa. 57\% of the rockbursts occur within $20 \mathrm{~m}$ of a geological structure although only $47 \%$ of mining takes place in this area.

- Dilatational/implosional failures also are observed. See:

- Gibowicz, [7], p 4, Poland.

- Joughin, [7], p 155, South Africa.

- Gibowicz, [7], p. 48, and Mc Garr, [7], p 156. Tensile failure gives compressional first motion. Implosion mechanisms do not.

\footnotetext{
* numbers in brackets give references, pp 6-7.
} 
- Mc Garr, [7], p 157. Much of mining-induced seismicity occurs by fracturing of previously intact rock rather than by displacement along pre-existing fractures. Note: to reconcile this with other statements above, one must distinguish between mere seismicity and rockbursts. This statement apparently is not made with regard to rockbursts. There are many more seismic events than there are rockbursts; in South African mines the ratio is 8 to 1 (Gay, [7], p 161).

- Lourence et al., [14], p 219, Coeur d Alene district, ID, U.S.A. $M=2.5$ implosional event in July 1992.

For the specific case of deep mines with longwall extraction and pillar support there seems to be general agreement that the rockburst problem is strongly related to the average energy release rate (ERR) associated with mining. (Tanton et al., [2], p 246) The ERR is proportional to the product of the stress acting on an area of rock prior to mining and its average displacement after mining (convergence). To reduce rockburst incidence the ERR must be reduced.

\section{ROCKBURST MAGNITUDES}

- Sweden : up to $\mathrm{M}_{\mathrm{L}}=3.2 ;$ Bath, [2], p 14 .

- Poland : $\mathrm{M}_{\mathrm{L}}=4.5$, Lubin; Gibowicz, [2], p 18

$$
\mathrm{M}_{\mathrm{L}}=4.6 \text {, Belchatow; Gibowicz, [2], p } 18
$$

- South Africa : $M=5.2$; shear on fault, Brunner and Rorke, [7], $\mathrm{p}$ 323. The same authors, indicate $M \leq 3.6$ for pillar crush, and $M$ seldom $>3.4$ for rock crushing at the face ([7], p 323).

Note: Johnston, [6], p 48, estimates the maximum potential magnitude for a nonfault rupture event to be up to 3.8 in "soft to medium hard" rock mines, and up to 4.8 in deep "hard rock" mines. No estimate is given for shear events.

\section{REMEDIAL/CONTROL MEASURES}

Mining engineers have long tried to reduce the severity and number of rockbursts. Generally this involves designing a mining plan which avoids creating high stress 
concentrations in pillars and remnants, or reducing confining stresses in the vicinity of faults. In addition, ground preconditioning/softening by drilling blasting has been performed (Karwosky [1], Haramy et al. [5], Morrison [7], p 429). Destressing by water injection also has been tried (Jianyun, [3]). These methods have met with success. On the other hand, changing the rate of production did not seem to have an influence on the occurrence of large events (Gay, [2], p 117).

But clearly, very little has been done in attempting to make rockbursts occur. If anything, it was noted that any such attempt by using mine blasting would be haphazard (Morrison, [7], p 429).

\section{ROCKBURST FORECASTING}

The literature concerning the prediction of rockburst occurrence contains the full range of statements from impossible, to possible, to already achieved.

The great majority of predictive tools is based on listening to and analyzing the seismic activity. Other methods which are reported include:

- measurement of rock mass resistivity changes, as related to stress changes; Stopinsky and Dmowska, [2], p 304, Poland.

- radon emissions, Mc Donald, [2], p 312, S. Africa.

- non-physical approaches, Cyrul, [10, 13], Poland.

- correlation with blasting: Swanson and Sines, [9], Idaho, USA. State that 75\% of rockbursts occur within 45 minutes of a mine blast.

- volume of recovered material vs. volume drilled, Jianyun and Jiayou, [3], coal mines, China.

None of these approaches have resulted in credible forecasting of rockbursts.

In the seismic monitoring arena several approaches have been used:

- study of "quiet" periods as precursors (Dechelette, [2], p 86; Shepherd et al., [2], p 104).

- increased microseismic activity was judged both as a good potential predictor (Brink, [2], p 321) and as an unreliable one (Leighton, [2], p 290).

- the fractal character of the clustering of seismic activity was judged as potentially useful (Xie and Pariseau, [12]).

Examples of pessimism as to the feasibility of prediction are those of Ortlepp, [14], $p$ 101 , who views the problem of rockbursts as "the single most intractable technical 
problem", and Udd, [4], p 1285, who believes that prediction in space is "attainable" but prediction in time may never be "feasible".

On the other hand, some are claiming success. Chavan et al. ([14], p 163, India) use a combination of "regularity" pattern of events and quantification of mine closure, and report predicting the date of occurrence and estimating the intensity of a rockburst. Lasocki ([14], p 214, Poland) using a Pareto statistical analysis of events distribution show a strong correlation between probability of occurrence and an actual rockburst event. More case histories are required to validate those prediction methods.

\section{SUMMARY - DISCUSSION}

An evasion scenario based on rockbursts is predicated upon someone's ability to make such an event occur in a controlled space and time fashion. Two things mitigate against such a possibility: the fact that no one has truly mastered an understanding of rockburst occurrences, and the fact that the energy of the mining profession has been totally focused on preventing these events.

Nevertheless, one could conceive of a scheme by which a controlled rockburst may be created. This would be in the context of deep, longwall, operations. It would be based on the notion of causality between high ERR and rockburst occurrence. A longwall mine could be operated so that temporary artificial supports be installed in the mined-out area as the face advances. By destroying these supports in an instant, a large caving of the unsupported ground could be provoked, hopefully within a matter of minutes to hours. The result would be a form of rockburst, which would be controlled in space (the stope location) and in time. The energy release may be coarsely estimated from in-situ stresses and stope closure and the resulting ground motion could be simulated with appropriate rock mass dynamics models.

Clearly, the nuclear burst would have to be located in the vicinity of the stope so as not to appear as a distinct event. In addition, the operators would need to guarantee that the mine burst would not affect the physical systems involved in the evasive shot.

In conclusion, I view the evasion scenario as highly risky and quite improbable, but not impossible. 


\section{REFERENCES}

1. Karwoski, W. J., Mc Laughlin, W. C., and Blake, W. (1979), "Rock Preconditioning to Prevent Rock Burst-Report on a Field Demonstration", U.S. Bureau of Mines RI $8381,45 \mathrm{p}$.

2. Gay, N. C., and Wainwright, E. H. Eds. (1984), Rockbursts and Seismicity in Mines, Proc. 1st Int. Symp., Johannesburg, S. Africa, 1982, 363 p., (S. African Inst. Mining Metal., Johannesburg). Contains 46 papers.

3. Jianyun, M., and Jiayou, L. (1987), "The Phenomena, Prediction, and Control of Rockbursts in China", Proc. 6th Congress Int. Soc. Rock Mech. Montreal, Canada, v. 2, pp 1135-1140, (A. A. Balkema, Brookfield, VT).

4. Udd, J. E., and Hedley, D. G. F. (1987), "Rockburst Research in Canada", Proc. 6th Congress Int. Soc. Rock Mech. Montreal, Canada, v. 2, pp 1283-1288, (A. A. Balkema, Brookfield, VT).

5. Haramy, K. Y., Mc Donnell, J. P., and Beckett, L. A. (1988), "Control of Coal Mine Bursts", Mining Engineering, April, pp 263-267.

6. Johnston, J. C. (1988), "A Survey of Mining-Associated Rockbursts", Air Force Geophysics Laboratory, Hanscome AFB, MA, AFGL-TR-88-0050 56 p.

7. Fairhurst, C. Ed. (1990), Rockbursts and Seismicity in Mines, Proc. 2nd Int. Symp. Minneapolis, MN, June 8-10, 1988, 439 p, (A. A. Balkema, Brookfield, VT). Contains 64 papers.

8. Jenkins, R. M., Williams, T. J., and Wideman, C. J. (1990), "Rockburst Mechanism Studies at the Lucky Friday Mine", Proc. 31st U. S. Symp. Rock Mechanics, Golden, CO, pp 955-962, (A. A. Balkema, Brookfield, VT).

9. Swanson, P. L., and Sines, C. D. (1991), "Characteristics of Mining-Induced Seismicity and Rock Bursting in a Deep Hard-Rock Mine", U. S. Brueau of Mines RI $9393,12 \mathrm{p}$.

10. Cyrul, T. (1992), "A Concept of Prediction of Rock and Gas Outbursts", Geotechnical and Geological Engineering, v. 10, n. 1, pp 1-17. 
11. Swanson, P. L., Estey, L. H., Boler, F. H., and Billington, S. (1993), "Accuracy and Prediction of Microseismic Event Locations in Rock Burst Research Studies", U. S. Bureau of Mines RI $9395,40 \mathrm{p}$.

12. Xie, H., and Pariseau, W. G. (1993) "Fractal Charactrer and Mechanism of Rock Bursts", Int. I. Rock Mechanics Mining Science, v. 30, n. 4, pp 343-350.

13. Cyrul, T. (1993), "Prediction of Rock and Gas Outburst Occurence", Engineering Geology, v. 33, n. 3, pp 241-250.

14. Young, P. Ed. (1993), Rockbursts and Seismicity in Mines 93, Proc. 3rd Int. Symp., Kingston, Ont., Aug. 16-18, 1993, 449 p, (A. A. Balekma, Brookfield, VT). Contains 71 papers.

\section{ACKNOWLEDGMENTS}

This work was performed with support from the Treaty Verification Program of Lawrence Livermore National Laboratory, under contract W-7405-ENG-48 with the U.S. Department of Energy.

Dr. Howard Patton was the project monitor. The fine typing of Susan Uhlhorn is gratefully acknowledged. 
